\title{
Identification and Antimicrobial Susceptibility Profile of Salmonella Isolated from Selected Dairy Farms, Abattoir and Humans at Asella Town, Ethiopia
}

\author{
Takele Beyene*, Habtie Yibeltie, Bulako Chebo, Fufa Abunna, Ashenafi Feyisa Beyi, Bedaso Mammo, Dinka Ayana and Reta Duguma \\ College of Veterinary Medicine and Agriculture, Addis Ababa University, PO Box 34, Bishoftu, Ethiopia \\ *Corresponding author: Takele Beyene, College of Veterinary Medicine and Agriculture, Addis Ababa University, PO Box 34, Bishoftu, Ethiopia, Tel: +251912828253; \\ E-mail: takele.beyene@aau.edu.et
}

Rec date: Jan 08, 2016; Acc date: Mar 25, 2016; Pub date: Mar 28, 2016

Copyright: $\odot 2016$ Beyene T, et al. This is an open-access article distributed under the terms of the Creative Commons Attribution License, which permits unrestricted use, distribution, and reproduction in any medium, provided the original author and source are credited.

\section{Abstract}

Salmonella is one of the most common causes of food-borne diarrheal disease in human as well as animals. It is leading causes of acute gastroenteritis when ingested in contaminated foods, including meat and dairy products. Moreover, the emergence of multiple-resistant (MDR) isolates is increasing in human and veterinary medicines. Therefore, this cross-sectional study aims at isolation, identification and antibiogram of Salmonella from selected dairy cattle farms, abattoir and in contact humans in both dairy farms and abattoir of Asella, Ethiopia.

We collected 185 samples from abattoir $(n=94)$ and dairy farms $(n=91)$, which were isolated and identified according to ISO-6579, 2002. The overall proportion of Salmonella was $6.5 \%(12 / 185)$ (dairy farms $n=4,4.4 \%$ and abattoir $n=8,8.5 \%$ ). Antibiogram of isolated Salmonella was also evaluated against ten commonly used antibiotics in both humans and veterinary medicines to treat salmonellosis by using the Kibry Bauer disk diffusion method. All isolates $(100 \%, \mathrm{n}=12)$ were susceptible to ciprofloxacin and gentamycin followed by $91.7 \%, 75 \%, 66.7 \%, 58.3$ and $50 \%$ of the isolates were susceptible to sulfamethoxazole-trimethoprim, chloramphenicol, kanamycin, nalidixic acid and streptomycin, respectively. However, cefoxitin showed the highest resistance $(66.7 \%)$ followed by ampicillin and amoxicillin $(58.3 \%$ each). Moreover, $50 \%$ of the isolates were resistant to two or more of the tested antimicrobial agents. The highest MDR was seen on polled hand swabs from abattoir, resistance to eight antimicrobials $(80 \%$, $n=8 / 10$ ) with the combination of cefoxitin, ampicillin, amoxicillin and streptomycin being more frequent.

High proportion of Salmonella was isolated from abattoir sample than dairy farms. These isolate developed MDR to commonly prescribed antimicrobial agents in the study area. Hence, strict hygienic management in the farm and abattoir as well as rational use of antimicrobials should be practised to circumvent the further development of antimicrobial resistance.

Keywords: Antibiogram; MDR; Ciprofloxacin; Gentamycin; Cefoxitin; Food safety; Antimicrobial resistance; Abattoir; Antibiotic resistance; Dairy farms; Humans; Isolation; Salmonella

\section{Abbreviations:}

AMR: Antimicrobial resistance; ARVL: Asella Regional Veterinary Laboratory; CI: Confidence Interval; CLSI: Clinical and Laboratory Standards Institute; ISO: International Organizations for Standardization; MDR: Multidrug-resistance; ml: Milliliter; SPSS: Statistical Product and Service Solution; $\chi^{2}$ : Chi square; $\mu$ g: Microgram.

\section{Introduction}

Food borne bacterial diseases are a serious challenge to human and animal health. The epidemiology of these diseases has changed rapidly because of changes in the social environment and the ability of pathogens to adapt to new niches. Salmonella is one of the most common causes of food borne diarrheal disease in human and animals. It is leading causes of acute gastroenteritis and an important public health problem worldwide particularly in the developing countries [1].
Salmonella transmits to humans can occur through several routes. These are consumption of contaminated food products (milk, eggs, and meats), direct contact with animals and their environment, cross contamination through direct contact of foods to contaminated surfaces such as stainless steel, hanging material, knife, bucket where milk are collected are a key mechanism for pathogens to contaminate food products [2,3]. Excretion of Salmonella with faeces can contaminate water, soil, other animals and feed [4]. Although Salmonella primarily intestinal bacteria, due to its ubiquitous nature common in the environment and commonly found in farm effluents, human sewage and in any materials subject to faecal contamination as a result it leads the contamination of milk and meat products to originate either from infected live animals or from cross contamination while during processing [5].

Fluoroquinolones, are effective on the majority of Salmonella strains, are usually regarded as the first line treatment of salmonellosis in adult humans [6]. Antimicrobial use in animal production systems has long been suspected to be a cause of the emergence and dissemination of antimicrobial resistant (AMR) Salmonella. Using antimicrobial agents for cattle have been implicated as a source of human infection with AMR Salmonella through direct contact with livestock and consumption of raw milk, meat and contaminated 
Citation: Beyene T, Yibeltie H, Chebo B, Abunna F, Beyi AF, et al. (2016) Identification and Antimicrobial Susceptibility Profile of Salmonella Isolated from Selected Dairy Farms, Abattoir and Humans at Asella Town, Ethiopia. J Veterinar Sci Techno 7: 320. doi: $10.4172 / 2157-7579.1000320$

Page 2 of 7

material [7]. AMR Salmonella are increasing due to the use of antimicrobial agents in food animals at sub therapeutic level or prophylactic doses that may promote growth and markedly increase the human health risks associated with consumption of contaminated milk and meat products [8] through mutation, acquisition of resistance encoding genes [9] and irrational use of antimicrobials in food animals $[9,10]$.

Different studies conducted in Ethiopia revealed fragmented substantial prevalence as well as antimicrobial susceptibility of Salmonella in veterinary medicines [8,10-15] and humans [16-18]. However, reports from coinciding study on apparently healthy animals at farm level, carcass at abattoir, and humans involved in working in farms and abattoir is limited. Therefore, the aim of this study were to isolate and identify Salmonella from cattle, cattle derivative food (meat and milk) and humans working in the selected dairy farms and abattoir at Asella district as well as compare and evaluate the antibiogram pattern of the isolates from different sources.

\section{Materials and Methods}

\section{Study area}

The study was conducted from January 2014 to April 2014 in selected dairy cattle farms and municipal abattoir found in Asella.
Asella is at 60591-80491 N latitude and 380411-400441E longitude in central Ethiopia $175 \mathrm{~km}$ south east of Addis Ababa. The altitude of the area ranges from 1780-3100 meter above sea level and characterized by mid subtropical temperature ranging from $5^{\circ} \mathrm{C}-28^{\circ} \mathrm{C}$. The annual average rainfall is $1200 \mathrm{~mm}$ and mostly with clay type of soil and in rare case black soil. The area covers 23674.72 square kilometres and topographically has highland escapement and lowland areas. The high land areas are found centrally and the low lands dominate the periphery of the area [19].

\section{Experimental design}

A cross-sectional study was conducted in selected dairy farms located in Asella with a target to supply milk for consumers and in Asella municipal abattoir which is the sole supplier of meat to the town. A total of 185 samples were considered from the abattoir $(n=94)$ and randomly selected cattle of all age and sex groups in the dairy farms $(n=91)$. The sample size was fixed based on representative samples taken from selected dairy cattle farms and municipal abattoir. Samples were collected (Table 1) from four selected dairy cattle farms including small scale farms and six abattoir visits.

\begin{tabular}{|c|c|c|c|c|c|}
\hline \multirow{2}{*}{ Sample source } & \multirow{2}{*}{ Sample type } & \multirow{2}{*}{$\begin{array}{l}\text { Total sample } \\
\text { collected }\end{array}$} & \multicolumn{2}{|c|}{ Salmonella status } & \multirow[t]{2}{*}{$\mathrm{X}^{2}$ (P-value) } \\
\hline & & & Negative & Positive (\%) & \\
\hline \multirow{7}{*}{ Abattoir } & Carcass swab & 28 & 27 & $1(3.6 \%)$ & \multirow{15}{*}{$1.29(0.256)$} \\
\hline & Hanging material swab & 7 & 6 & $1(14.3 \%)$ & \\
\hline & Knife swab & 6 & 5 & $1(16.7 \%)$ & \\
\hline & Hand swab & 7 & 5 & $2(28.6 \%)$ & \\
\hline & lymph node & 23 & 20 & $3(13.0 \%)$ & \\
\hline & Faeces & 23 & 23 & $0(0.0 \%)$ & \\
\hline & Subtotal & 94 & 86 & $8(9.3 \%)$ & \\
\hline \multirow{8}{*}{ Dairy farm } & Milk & 36 & 36 & $0(0.0 \%)$ & \\
\hline & Tank milk & 7 & 6 & $1(14.3 \%)$ & \\
\hline & Faeces from farm & 27 & 26 & $1(3.7 \%)$ & \\
\hline & Bucket swab & 7 & 6 & $1(14.3 \%)$ & \\
\hline & Hand swab & 7 & 7 & $0(0.0 \%)$ & \\
\hline & Tank swab & 7 & 6 & $1(14.3 \%)$ & \\
\hline & Subtotal & 91 & 87 & $4(4.6 \%)$ & \\
\hline & Total & 185 & $173(93.5 \%)$ & $12(6.5 \%)$ & \\
\hline
\end{tabular}

Table 1: Proportion of Salmonella isolated from different samples of dairy farms, abattoir and individuals working in the dairy farms and abattoir.

\section{Specimen collection, transportation and storage}

Samples from dairy cows, cattle derivative foods (milk and meat), utensils and personnel working in the farms and abattoir were aseptically collected directly from randomly selected apparently healthy dairy cattle in the farm and beef cattle in Asella municipal abattoir. Faecal samples were collected directly from the rectum and put into $50 \mathrm{ml}$ containing universal screwed caped bottle and approximately $10 \mathrm{ml}$ of milk was collected aseptically from all teats in a sterile test tube. A pooled swab of carcass, hanging material, lymph 
Citation: Beyene T, Yibeltie H, Chebo B, Abunna F, Beyi AF, et al. (2016) Identification and Antimicrobial Susceptibility Profile of Salmonella Isolated from Selected Dairy Farms, Abattoir and Humans at Asella Town, Ethiopia. J Veterinar Sci Techno 7: 320. doi: $10.4172 / 2157-7579.1000320$

Page 3 of 7

node, hand, tank and bucket was collected by using a sterile wooden cotton swab on the surface of material and insert in the $10 \mathrm{ml}$ test tube that contains sterile buffered peptone water used as a pre enrichment media for $24 \mathrm{hrs}$ at $37^{\circ} \mathrm{C}$. Then, within 24 hours, the samples were transported using icebox containing ice bag and analysed at the Asella regional veterinary laboratory (ARVL).

\section{Bacterial culture}

The isolation and identification of Salmonella from faeces, lymph node, hanging material, knife swab, hand swab, milk and meat was performed at the ARVL by using techniques recommended by International Organizations for Standardization [20]. It involves three steps, $5 \mathrm{gm}$ of faecal sample or $5 \mathrm{ml}$ of milk was pre-enriched with 45 $\mathrm{ml}$ of BPW at a ratio of 1:9 and swabs taken from abattoir and farm such as hanging material, knife, hand, bucket and tank was preenriched with $10 \mathrm{ml} \mathrm{BPW}$ and incubated for $24 \mathrm{hrs}$ at $37^{\circ} \mathrm{C}$. One $\mathrm{ml}$ of the pre-enriched culture was transferred to $10 \mathrm{ml}$ of Selenite F Broth (SFB) tube and another $0.1 \mathrm{ml}$ portion was transferred to $10 \mathrm{ml}$ of Rappaport Vassiliadis Soy Broth (RVSB) and incubated at $37^{\circ} \mathrm{C}$ for 24 hrs and 48 hrs, respectively. Finally one loop of broth culture from the inoculated and incubated SFB and RVSB sample was inoculated and incubated on to Xylose Lysine Deoxycholate (XLD) at $37^{\circ} \mathrm{C}$ for $48 \mathrm{hrs}$ and Salmonella Shigella (S-S) agar at $37^{\circ} \mathrm{C}$ for $24 \mathrm{hrs}$. Characteristic Salmonella colonies, having a slightly transparent zone of reddish colour and a black centre on XLD media and typical Salmonella colonies on S-S agar plate cause the colour of the medium to be colorless or transparent colony with black centre.

When suspected colonies were detected, sub cultivation of 4 Salmonella colonies from XLD and S-S agar on to a non-selective nutrient agar media plates for confirmation by using biochemical tests including Triple sugar iron agar (TSI), Indole test, urease test, Simon's citrate test, and Methyl red-Vogues proskeurs (MR-VP) test. Atypical biochemical reaction on TSI i.e., alkaline (red) slant, acidic (yellow) butt, $\mathrm{H}_{2} \mathrm{~S}$ and gas production, citrate utilization as a carbon source, Indole and urease negative, M-R positive, and V-P negative [21] were performed.

\section{Antibiogram of the isolates}

Antibiogram of Salmonella isolates was tested against ten different antibiotics, namely amoxicillin $(25 \mu \mathrm{g})$, ampicillin $(10 \mu \mathrm{g})$, cefoxitin $(30 \mu \mathrm{g})$, chloramphenicol $(30 \mu \mathrm{g})$, gentamycin $(10 \mu \mathrm{g})$, streptomycin $(10 \mu \mathrm{g})$, kanamycin $(30 \mu \mathrm{g})$, nalidixic acid $(30 \mu \mathrm{g})$, ciprofloxacin $(5 \mu \mathrm{g})$ and sulfamethoxazole-trimethoprim $(25 \mu \mathrm{g})$, all from Oxoid company, England by using Kibry-Bauer disk diffusion method following Clinical and Laboratory Standards Institute guidelines [22].

From each isolate, four biochemically confirmed well-isolated colonies grown on nutrient agar were transferred into tubes containing $5 \mathrm{ml}$ of Tryptone soya broth (Oxoid, England). The broth culture was incubated at $37^{\circ} \mathrm{C}$ for $4 \mathrm{hrs}$ until it achieved the 0.5 McFarland turbidity standards. Sterile cotton swab was dipped into the suspension and the bacteria were swabbed uniformly over the surface of MullerHinton agar plate (Oxiod CM 0337 Basingstoke, England) with in a sterile safety cabinet. The plates were held at room temperature for 15 minutes to allow drying. Antibiotic discs with known concentration of antimicrobials were placed and the plates were incubated for $24 \mathrm{hrs}$ at $37^{\circ} \mathrm{C}$.

Following incubation, the diameters of zone of inhibition was recorded to nearest millimetres for each disc used and then classified as resistant, intermediate, and susceptible according to published interpretive chart of CLSI [22].

\section{Statistical analysis}

Data entry and management was done using program Microsoft Office Excel 2010 and then analysed by using SPSS Version 20 computer software. The association between salmonella status and sample source and the antibiotic sensitivity pattern of isolated Salmonella were compared statistically by using Fisher exact test with significance level defined at the p-value less than 0.05 and 95\% CI.

Ethical consideration: The Institutional Review Board of College of Veterinary Medicine and Agriculture, Addis Ababa University ethically approved the study. Moreover, both informed and written consent were obtained from the human subjects. Confidentiality of the human participants, abattoir and the dairy farms were maintained by using unique code.

\section{Results and Discussion}

\section{Isolation and identification of Salmonella}

Salmonella is considered as an important food borne bacterial pathogens. In this study, of 185 samples collected from selected dairy farms and abattoir, it was found that the proportion of Salmonella isolated from dairy farms, apparently healthy slaughtered cattle in municipal abattoir and materials used in the process of food along with personnel's hand swab was $6.5 \%(n=12)$. Among the isolates, the relative overall proportion of Salmonella at farm level was found to be $4.4 \%(4 / 91)$ and at abattoir $8.5 \%(8 / 94)$. However, there was no statistically significant association between the Salmonella status and sample source collected from abattoir and farm $\left(\chi^{2}=1.291, \mathrm{p}=0.256\right)$. The proportion of Salmonella isolated in this study is lower than previous studies conducted in Ethiopia 20\% in raw milk from Korsa district [23], $10.76 \%$ in lactating cows and in contact humans in dairy farms of Addis Ababa [11], 7.2\% in slaughtered small ruminants and environment in Modjo export abattoir [24] and 7.1\% from apparently healthy slaughtered cattle in Debre Zeit [14]. However, it is higher than the previous study on dairy product in Addis Ababa $(1.6 \%)[25,26]$ and cheese and milk in Debre Zeit (2.1\%) [8].

In the present study, the proportion of Salmonella on individual sample of carcass swab was $3.6 \%$, mesenteric lymph nodes $(13.0 \%)$, and pooled knife swabs (16.7\%) and pooled hand swabs (28.6\%) from abattoir (Table 1). This study has also shown higher proportional isolation of Salmonella than report from knife swab (7.4\%) and hand swab (8.9\%), similar to that reported from mesenteric lymph node (13.0\%), but lower isolation from carcass swab (25.0\%) than the work of Teklu and Negussie [24]. The reason could be associated with the hygienic status of the abattoir and cross contamination among the materials used in the slaughtering operation and processing of food. The difference in proportion of Salmonella isolation between the present studies from the previous studies at different areas of the country could be associated with different risk factors that contribute to the occurrence of Salmonella. These are host related risk factors that include age, breed, the physiological state of the animals, feeding strategies, vaccination status [26]. Environment related risk factors are often related to hygienic and management practice, stocking density, type and amounts of feed, accessible water supplies, infection load in the environment, usage of contaminated utensil, housing type, ventilation, flooded grassing areas, movement of animals, calving 
Citation: Beyene T, Yibeltie H, Chebo B, Abunna F, Beyi AF, et al. (2016) Identification and Antimicrobial Susceptibility Profile of Salmonella Isolated from Selected Dairy Farms, Abattoir and Humans at Asella Town, Ethiopia. J Veterinar Sci Techno 7: 320. doi: $10.4172 / 2157-7579.1000320$

Page 4 of 7

environment, and production facilities in different areas are also plays a role for Salmonella occurrence [27]. Additionally, epidemiological patterns of Salmonella differ greatly between geographical areas depending on climate, population density, land use, farming practice, food harvesting and processing technologies and consumer habits [28].

In the current study though relatively low proportion of Salmonella (6.5\%) was isolated and identified compared to previous studies, it might pose a significant health risks to humans and animal species to cause salmonellosis in high-risk groups such as new-borns, infants, and the elderly and immune compromised individuals susceptible to Salmonella infections at a lower infective dose than healthy adults are. Therefore, it is a source of Salmonella infection through consumption of contaminated dairy products, which is mainly important in Ethiopia in general and Asella in particular, where dairy products are frequently consumed without proper boiling.

\section{Antimicrobial susceptibility testing}

Salmonella isolates $(\mathrm{n}=12)$ were tested against ten commonly used antimicrobials following CLSI [22] guidelines. The results of antimicrobial susceptibility testing showed that $66.7 \%, 58.3 \%$, and $41.7 \%$ resistance to cefoxitin, amoxicillin/ampicillin and streptomycin, respectively while $100 \%$ sensitive was recorded to ciprofloxacin and gentamycin followed by $91.7 \%, 75.0 \%$ and $58.3 \%$ sensitive to sulphametoxazole-trimethoprim, chloramphenicol and kanamycin respectively (Table 2 ).

\begin{tabular}{|l|l|l|l|}
\hline \multirow{2}{*}{ Antimicrobials tested } & \multicolumn{3}{|l|}{$\begin{array}{l}\text { Status of antimicrobial agent against the } \\
\text { isolates }\end{array}$} \\
\cline { 2 - 4 } & $\begin{array}{l}\text { Resistant } \\
(\%)\end{array}$ & $\begin{array}{l}\text { Intermediate } \\
(\%)\end{array}$ & $\begin{array}{l}\text { Susceptible } \\
(\%)\end{array}$ \\
\hline Amoxicillin & $7(58.3 \%)$ & $1(8.3 \%)$ & $4(33.3 \%)$ \\
\hline Ampicillin & $7(58.3 \%)$ & $4(33.3 \%)$ & $1(8.3 \%)$ \\
\hline Cefoxitin & $8(66.7 \%)$ & $0(0.0 \%)$ & $4(33.3 \%)$ \\
\hline Chloramphenicol & $2(16.7 \%)$ & $1(8.3 \%)$ & $9(75.0 \%)$ \\
\hline Ciprofloxacin & $0(0.0 \%)$ & $0(0.0 \%)$ & $12(100 \%)$ \\
\hline Gentamycin & $0(0.0 \%)$ & $0(0.0 \%)$ & $12(100 \%)$ \\
\hline Kanamycin & $2(16.7 \%)$ & $3(25.0 \%)$ & $7(58.3 \%)$ \\
\hline Nalidixic acid & $1(8.3 \%)$ & $3(25.0 \%)$ & $8(66.7 \%)$ \\
\hline Streptomycin & $5(41.7 \%)$ & $1(8.3 \%)$ & $6(50.0 \%)$ \\
\hline $\begin{array}{l}\text { Sulphametoxazole- } \\
\text { Trimethoprim }\end{array}$ & $1(8.3 \%)$ & $0(0.0 \%)$ & $11(91.7 \%)$ \\
\hline
\end{tabular}

Table 2: Antimicrobial susceptibility profile of Salmonella isolated from dairy cattle, abattoir and humans working in the dairy farms and abattoir.

The result for streptomycin resistance in this study (41.7\%) was higher than $13.3 \%$ and $25 \%$, which was reported by Addis et al. [11] and Tadesse and Anbessa [23], respectively. However, the finding for ampicillin is slight higher than the findings of other investigators in Ethiopia (50\%) by Tesfaw et al. [25] but lower than $100 \%$ reported by Addis et al. [11] whereas the findings for amoxicillin is higher than $16.7 \%$ reported by Tesfaw et al. [25]. The resistance of chloramphenicol in this study is consistent with $16.7 \%$ reported by Tesfaw et al. [25] and
Addis et al. [11], and lower than $25 \%$ reported by Tadesse and Anbessa [23]. The effectiveness of gentamycin and ciprofloxacin to isolated Salmonella in this study (100\%) is similar to the result reported by Tesfaw et al. [23], but higher than $73.3 \%$ and $83.3 \%$ reported by Addis et al. and $75 \%$ and $95 \%$ reported by Tadesse and Anbessa [23] for both antimicrobial agents, respectively. This difference might be due to small sample sizes for the data, nature of drug, presence of different strain of the bacteria, development of resistant gene, their low frequency usage for prevention and control of disease in food animals in the study area.

Among the 12 Salmonella isolates subjected to the antimicrobial susceptibility testing, the majority of the isolates $(83.3 \%, n=10 / 12)$ were resistant to at least one or more drugs tested. The result is in line with different studies conducted in Ethiopia by Dabassa and Bacha [29] Tadesse and Anbessa [23] and Tesfaw et al. [25].

In the present study, $50 \%$ of the isolates were resistant to at least three or more types of antimicrobials (MDR) and to single type of antibiotic (16.7\%) (Table 3) compared with the work of Tadesse and Anbessa [23] who reported $70 \%$ and 30\%, Dabassa and Bacha [29] who report $83.3 \%$ and $16.3 \%$, and also Tesfaw et al. [25] who reported $50 \%$ and $50 \%$ for multiple and single antimicrobial resistance, respectively.

\begin{tabular}{|l|l|l|}
\hline $\begin{array}{l}\text { Number } \\
\text { of AMR }\end{array}$ & Antimicrobials shown resistance & $\begin{array}{l}\text { Number of } \\
\text { isolates (\%) }\end{array}$ \\
\hline 0 & None & $2(16.7 \%)$ \\
\hline \multirow{2}{*}{1} & AML & $2(16.7 \%)$ \\
\cline { 2 - 3 } & FOX & $2(16.7 \%)$ \\
\hline \multirow{2}{*}{2} & FOX+S & \\
\cline { 2 - 3 } & AMP+FOX & $3(25.0 \%)$ \\
\hline \multirow{2}{*}{3} & AML+AMP+FOX & \\
\cline { 2 - 3 } & AML+AMP+FOX & $2(16.7 \%)$ \\
\cline { 2 - 3 } & AML+AMP+S & $1(8.3 \%)$ \\
\hline \multirow{2}{*}{5} & AML+AMP+FOX+C+S, AML+AMP+FOX+K+S & \\
\hline 6 & AML+AMP+FOX+C+K+NA+S+SMT & \\
\hline
\end{tabular}

Table 3: Antimicrobial susceptibility pattern of Salmonella isolates from different samples of dairy farms, abattoir and individuals working in the dairy farms and abattoir. AMR: antimicrobial resistance; AML: Amoxicillin; AMP: Ampicillin; FOX: Cefoxitin; C: chloramphenicol; K: Kanamycin; NA: Nalidixic acid; S: Streptomycin; SMT: Sulphametoxazole-trimethoprim.

The highest MDR was seen on polled hand swabs from abattoir for eight antimicrobials with the combination of cefoxitin, ampicillin, amoxicillin and streptomycin being more frequent followed by hanging material and knife swabs with a value of five antimicrobials, respectively (Table 4). The difference in AMR level of Salmonella in different areas of the country was related to agent risk factors, which might be virulence, pathogenicity, infectiousness, antibiotic resistance, and host specificity mostly determined by the genetic composition of Salmonella strain [27]; and other possible causes could be increasing rate of non-rational use of antibiotics in the dairy farms, frequent usage both in livestock and public health, use of counterfeit drugs in 
Citation: Beyene T, Yibeltie H, Chebo B, Abunna F, Beyi AF, et al. (2016) Identification and Antimicrobial Susceptibility Profile of Salmonella Isolated from Selected Dairy Farms, Abattoir and Humans at Asella Town, Ethiopia. J Veterinar Sci Techno 7: 320. doi: $10.4172 / 2157-7579.1000320$

Page 5 of 7

animal husbandry [30] self-medication due to easy access to antibiotics without prescription in public health sector and administration of sub therapeutic dose of antimicrobials to livestock for prophylactic or nutritional purpose in food animals $[31,32]$.

\begin{tabular}{|c|c|c|c|c|c|c|c|c|c|c|}
\hline \multirow{2}{*}{ Name of antimicrobial agent } & \multirow{2}{*}{ Level } & \multicolumn{9}{|c|}{ Number of Salmonella isolated and percent of their susceptibility for different antimicrobial agents } \\
\hline & & $\mathrm{BS}(1)$ & $\operatorname{cs}(1)$ & $\mathrm{FF}(1)$ & HS(2) & $\mathrm{HM}(1)$ & KS(1) & LN(3) & $\mathrm{TM}(1)$ & $\mathrm{TS}(1)$ \\
\hline \multirow{3}{*}{ Ampicillin } & s & 0 & 100 & 0 & 0 & 0 & 0 & 0 & 0 & 0 \\
\hline & 1 & 100 & 0 & 100 & 0 & 0 & 0 & 66.7 & 0 & 0 \\
\hline & $\mathrm{R}$ & 0 & 0 & 0 & 100 & 100 & 100 & 33.3 & 100 & 100 \\
\hline \multirow{3}{*}{ Amoxicillin } & $\mathrm{s}$ & 100 & 0 & 0 & 0 & 0 & 0 & 66.7 & 100 & 0 \\
\hline & I & 0 & 0 & 100 & 0 & 0 & 0 & 0 & 0 & 0 \\
\hline & $\mathrm{R}$ & 0 & 100 & 0 & 100 & 100 & 100 & 33.3 & 0 & 100 \\
\hline \multirow{3}{*}{ Streptomycin } & S & 0 & 100 & 100 & 50 & 0 & 0 & 66.7 & 0 & 100 \\
\hline & 1 & 0 & 0 & 0 & 0 & 0 & 0 & 0 & 100 & 0 \\
\hline & $R$ & 100 & 0 & 0 & 50 & 100 & 100 & 33.3 & 0 & 0 \\
\hline \multirow{3}{*}{ Kanamycin } & $\mathrm{s}$ & 100 & 100 & 100 & 0 & 0 & 100 & 100 & 0 & 0 \\
\hline & 1 & 0 & 0 & 0 & 50 & 0 & 0 & 0 & 100 & 100 \\
\hline & $\mathrm{R}$ & 0 & 0 & 0 & 50 & 100 & 0 & 0 & 0 & 0 \\
\hline \multirow{3}{*}{ Nalidixic acid } & $S$ & 100 & 100 & 100 & 50 & 0 & 100 & 66.7 & 100 & 0 \\
\hline & 1 & 0 & 0 & 0 & 0 & 100 & 0 & 33.3 & 0 & 100 \\
\hline & $\mathrm{R}$ & 0 & 0 & 0 & 50 & 0 & 0 & 0 & 0 & 0 \\
\hline \multirow{3}{*}{ Ciprofloxacin } & S & 100 & 100 & 100 & 100 & 100 & 100 & 100 & 100 & 100 \\
\hline & 1 & 0 & 0 & 0 & 0 & 0 & 0 & 0 & 0 & 0 \\
\hline & $\mathrm{R}$ & 0 & 0 & 0 & 0 & 0 & 0 & 0 & 0 & 0 \\
\hline \multirow{3}{*}{ Chloramphenicol } & S & 100 & 100 & 100 & 50 & 100 & 0 & 66.7 & 100 & 100 \\
\hline & 1 & 0 & 0 & 0 & 0 & 0 & 0 & 33.3 & 0 & 0 \\
\hline & $\mathrm{R}$ & 0 & 0 & 0 & 50 & 0 & 100 & 0 & 0 & 0 \\
\hline \multirow{3}{*}{ Cefoxitin } & 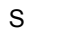 & 0 & 100 & 0 & 0 & 0 & 0 & 100 & 0 & 0 \\
\hline & 1 & 0 & 0 & 0 & 0 & 0 & 0 & 0 & 0 & 0 \\
\hline & $R$ & 100 & 0 & 100 & 100 & 100 & 100 & 0 & 100 & 100 \\
\hline \multirow{3}{*}{ Gentamycin } & S & 100 & 100 & 100 & 100 & 100 & 100 & 100 & 100 & 100 \\
\hline & 1 & 0 & 0 & 0 & 0 & 0 & 0 & 0 & 0 & 0 \\
\hline & $\mathrm{R}$ & 0 & 0 & 0 & 0 & 0 & 0 & 0 & 0 & 0 \\
\hline \multirow{3}{*}{$\begin{array}{l}\text { Sulfamethoxazole- } \\
\text { Trimethoprim }\end{array}$} & $s$ & 100 & 100 & 100 & 50 & 100 & 100 & 100 & 100 & 100 \\
\hline & 1 & 0 & 0 & 0 & 0 & 0 & 0 & 0 & 0 & 0 \\
\hline & $\mathrm{R}$ & 0 & 0 & 0 & 50 & 0 & 0 & 0 & 0 & 0 \\
\hline MDRa & $\mathrm{N}$ & 100 & 100 & 100 & 0 & 0 & 0 & 66.7 & 100 & 0 \\
\hline
\end{tabular}


Citation: Beyene T, Yibeltie H, Chebo B, Abunna F, Beyi AF, et al. (2016) Identification and Antimicrobial Susceptibility Profile of Salmonella Isolated from Selected Dairy Farms, Abattoir and Humans at Asella Town, Ethiopia. J Veterinar Sci Techno 7: 320. doi: $10.4172 / 2157-7579.1000320$

Page 6 of 7

\begin{tabular}{|l|l|l|l|l|l|l|l|l|l|l|}
\hline & $Y$ & 0 & 0 & 0 & 100 & 100 & 100 & 33.3 & 0 & 100 \\
\hline
\end{tabular}

Table 4: Antimicrobial resistance level of Salmonella isolated from different samples of dairy farms, abattoir and individuals working in the dairy farms and abattoir. BS: Bucket swab; CS: Carcass swab; FF: Faeces from farm; HS: Polled hand swab from abattoir; KS: Polled Knife swab; LN: Lymph node; TM: Tank milk; TS: Tank swab; HM: Polled hanging material; S: S Susceptible; I: Intermediate; R: Resistant; MDR: Multi-drug resistance; a: resistant to three or more of the tested antimicrobial agent.

In general, antimicrobial use is a key driver of resistance development, which is either over use for minor infectious, misuse due to lack of access to appropriate treatment and underuse due to inadequate dosing, poor adherence or substandard antimicrobial and lack of financial support to complete treatment course. The present study indicated importance of cattle products (milk and meat) and materials used for processing of these products as potential source of Salmonella infection.

\section{Conclusions}

Salmonella was isolated from cattle, cattle derivative food and in contact humans in dairy farms and abattoir, which are a potential source of AMR Salmonella infection. The overall prevalence of Salmonella was $6.5 \%$, where the prevalence in selected dairy farms and municipal abattoir was $4.4 \%$ and $8.5 \%$, respectively. Ciprofloxacin and gentamycin are the most effective antibiotics whereas cefoxitin, ampicillin and amoxicillin showed the highest resistance. Half of the tested Salmonella isolates was resistant to three or more of the tested antimicrobial agents that are commonly used in the veterinary and human medicines. This might limit therapeutic choice to manage salmonellosis and other bacterial diseases both in animal and human health care. Therefore, further detailed studies should be conducted to describe the common Salmonella serovars isolated from animals and humans in the study area and molecular characterization of the isolates resistant genes to identify the mechanism of AMR development.

\section{Competing Interests}

None of the authors has any competing interests.

\section{Authors' Contributions}

TB participated in research coordination, study design, data analysis, antibiogram, and manuscript drafting and final revision. HY participated in sample collection, bacterial culture and identification, antibiogram and drafting manuscript. BC participated in study supervision, bacterial identification and antibiogram. RD conceived the research idea and participated in its design, coordination and data analysis. FA, AF, DA, BM coordinated and supervised the study, provided valuable information on the subject of and the design of the study. All authors agreed with the results and conclusions; and read and approved the final manuscript.

\section{Acknowledgements}

The research is fully funded by Addis Ababa University (AAU). Hence, the researchers would like to thank Addis Ababa University Office of the Vice President for Research and technology Transfer for financial and other supports. We also acknowledge the priceless support given by the Asella abattoir and people working in selected dairy farms found in the Asella.

\section{References}

1. Ponce E, Khan AA, Cheng CM, Summage-West C, Cerniglia CE (2008) Prevalence and characterization of Salmonella enterica serovar Weltevreden from imported seafood. Food Microbiol 25: 29-35.

2. Plym F, Wierup M (2006) Salmonella contamination: a significant challenge to the global marketing of animal food products. Rev Sci Tech 25: 541-554.

3. Kusumaningrum HD, Riboldi G, Hazeleger WC, Beumer RR (2003) Survival of foodborne pathogens on stainless steel surfaces and crosscontamination to foods. Int J Food Microbiol 85: 227-236.

4. D'Aoust JY, Doyle MP, Beuchat LR, Montville TJ (1997) Salmonella Species. Food microbiology Fundamentals and Frontiers (3rd edn) ASM Press: Washington DC, USA, pp: 129-158.

5. Dahl J (1999) Success rate for eradication of Salmonella by cleaning and restocking pig herds and the use of ante mortem blood samples in herds after restocking. In: Proceedings, The 3rd International Symposium on Epidemiology and Control of Salmonella in pork, Washington DC, USA.

6. Leila Y (2012) Antibiotic resistance in salmonella enteric and the role of animal and animal food control. A literature review of Europe and USA. (2nd edn), pp: 12-13.

7. Alexander KA, Warnick LD, Wiedmann M (2009) Antimicrobial resistant Salmonella in dairy cattle in the United States. Vet Res Commun 33: 191-209.

8. Zewdu E, Cornelius P (2009) Antimicrobial resistance pattern of Salmonella serotypes isolated from food items and personnel in Addis Ababa, Ethiopia. Trop Anim Health Prod 41: 241-249.

9. Fluit AC (2005) Towards more virulent and antibiotic-resistant Salmonella. FEMS Immunol Med Microbiol 43: 1-11.

10. Beyene T, Tesega B (2014) Rational veterinary drug use: Its significance in public health. J Vet Med Hlth 6: 302-308.

11. Addis Z, Kebede N, Worku Z, Gezahegn H, Yirsaw A, et al. (2011) Prevalence and antimicrobial resistance of Salmonella isolated from lactating cows and in contact humans in dairy farms of Addis Ababa: a cross sectional study. BMC Infect Dis 11: 222.

12. Molla W, Molla B, Alemayehu D, Muckle A, Cole L, et al. (2006) Occurrence and antimicrobial resistance of Salmonella serovars in apparently healthy slaughtered sheep and goats of central Ethiopia. Trop Anim Health Prod 38: 455-462.

13. Ejeta G, Molla B, Alemayehu D, Muckle A (2004) Salmonella serotypes isolated from minced meat beef, mutton and pork in Addis Ababa, Ethiopia. Revue Med Vet 155: 547-551.

14. Alemayehu D, Molla B, Muckle A (2003) Prevalence and antimicrobial resistance pattern of Salmonella isolates from apparently healthy slaughtered cattle in Ethiopia. Trop Anim Hlth Prod 35: 309-319.

15. Molla B, Mesfin A, Alemayehu D (2003) Multiple antimicrobial resistant Salmonella serotypes isolated from chicken carcases and giblets in Debre Zeit and Addis Ababa, Ethiopia. Ethiop J Health Dev 17: 131-149.

16. Garedew L, Hagos Z, Addis A, Tesfaye T, Zegeye B (2015) Prevalence and antimicrobial susceptibility patterns of Salmonella isolates in association with hygienic status from butcher shops in Gondar town, Ethiopia. Antimicrob Resist Infect Control 4: 21.

17. Garedew-Kifelew L, Wondafrash N, Feleke A (2014) Identification of drug-resistant Salmonella from food handlers at the University of Gondar, Ethiopia. BMC Res Notes 7: 545. 
Citation: Beyene T, Yibeltie H, Chebo B, Abunna F, Beyi AF, et al. (2016) Identification and Antimicrobial Susceptibility Profile of Salmonella Isolated from Selected Dairy Farms, Abattoir and Humans at Asella Town, Ethiopia. J Veterinar Sci Techno 7: 320. doi: $10.4172 / 2157-7579.1000320$

Page 7 of 7

18. Mengistu G, Mulugeta G, Lema T, Aseffa A (2014) Prevalence and Antimicrobial Susceptibility Patterns of Salmonella serovars and Shigella species J Microbial Biochem Technol.

19. Arsi Plan and Economic Development Office (2007) Socio Economic on Arsi Zone. Asella, Ethiopia, pp: 1-105.

20. ISO-6579 (2002) Microbiology. General guidance methods for the detection of salmonella (4th edn). International organization for organization, Geneva, Switzerland. pp: 132-146.

21. Hendriksen RS (2003) A global Salmonella surveillance and laboratory support project of the World Health Organization: Laboratory Protocols (Isolation of Salmonella). (4th edn), pp: 253-278.

22. CLSI (Clinical and Laboratory Standards Institute) (2008) Performance standards for antimicrobial disk and dilution susceptibility tests for bacteria isolated from animals. Cli Lab Stand Inst 28: 31-133.

23. Tadesse T, Anbessa D (2012) Prevalence and antimicrobial resistance of Salmonella isolated from raw milk samples collected from Kersa District, Jimma Zone, South-West Ethiopia. J Med Sci 12: 224-228.

24. Teklu A, Negussie H (2011) Assessment of risk factors and prevalence of Salmonella in slaughtered small ruminants and environment in an export abattoir, Modjo, Ethiopia. J Agric and Environ Sci 10: 992-999.

25. Tesfaw L, Taye B, Alemu S, Alemayehu H, Sisay Z, et al. (2013) Prevalence and antimicrobial resistance profile of Salmonella isolates from dairy products in Addis Ababa, Ethiopia. Glob J Ind Microbiol 1: 23-27.
26. Liza RN (2003) Salmonella dublin in dairy cattle use of diagnostic tests for investigation of risk factors and infection dynamics. PhD Thesis, Department of Animal Science and Animal Health, the Royal Veterinary and Agricultural University, pp: 13-121.

27. Karin H, Andrea IM, Martin W (2011) Animal contact as a source of human non-typhoidal salmonellosis. J Vet Res 42: 1-28.

28. Radostits OM, Blood DC, Gay CC (1994) Veterinary Medicine, a Text Book of the Diseases of Cattle, Sheep, Pigs, Goats and Horses. (8th edn) Ballier Tindal: London, pp: 730-747.

29. Dabassa A, Bacha K (2012) The prevalence and antibiogram of salmonella and shigella isolated from abattoir, Jimma Town, South West Ethiopia. Int J Pharm Biol Res 3: 143-148.

30. Guthrie RK (1992) Salmonella. CRS press: USA, pp: 23-156.

31. Acha P, Szyfers B (2001) Zoonoses and Communicable Diseases Common to Man and Animals. Bacteriosis and Mycosis, Washington DC, Pan Amer Heal Org 1: 233-246.

32. Birhanu T, Abda S, Gebrezgabiher G (2014) Prevalence of Salmonella on Sheep Carcasses Slaughtered at Adama Municipal Abattoir, South Eastern Ethiopia. Sci Technol Arts Res J 3: 107-111. 